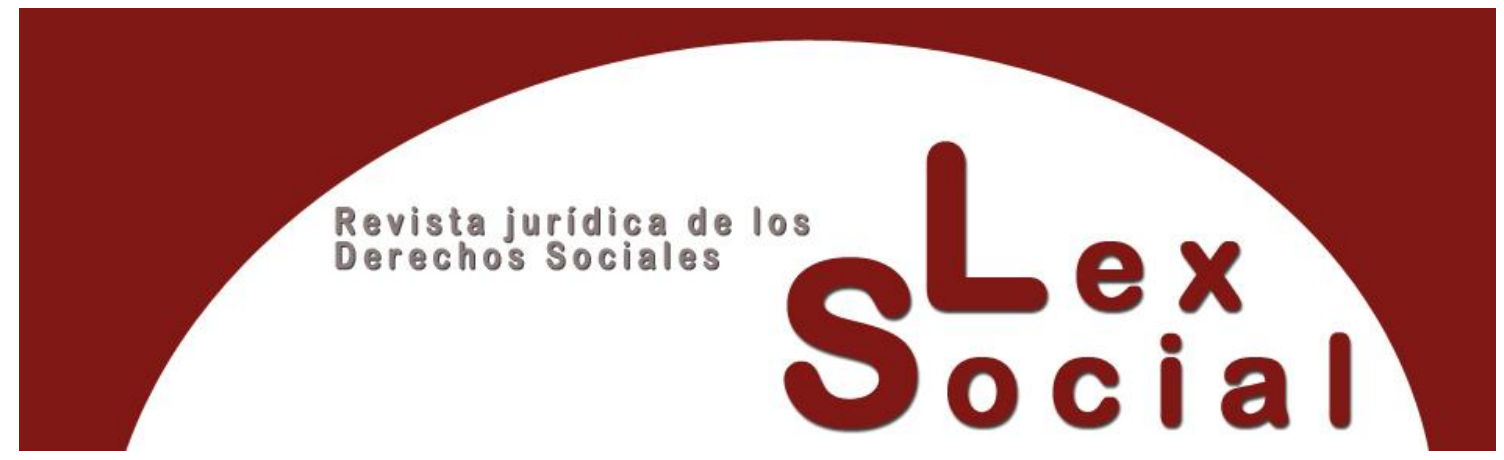

\title{
TRABAJO DE CUIDADOS: TENSIONES DERIVADAS DE SU DEFINICIÓN, SUS REGÍMENES DE FUNCIONAMIENTO Y SU ORGANIZACIÓN SOCIAL
}

\section{CARE WORK: TENSIONS CREATED BY ITS DEFINITION, ITS OPERATING REGIMES, AND ITS SOCIAL ORGANIZATION}

\author{
ELENA CACHÓN GONZÁLEZ \\ Universidad a Distancia de Madrid \\ https://orcid.org/0000-0002-8946-2919
}

Cómo citar este trabajo: Cachón González, E. (2021). Trabajo de cuidados: tensiones derivadas de su definición, sus regímenes de funcionamiento y su organización social. Lex Social: Revista De Derechos Sociales, 11(1), 558-586. https://doi.org/10.46661/lexsocial.5498

\section{RESUMEN}

Desde el análisis de las distintas definiciones de los cuidados, y bajo la doble perspectiva de la ética del cuidado y los vínculos con la teoría de género, se trabajará en torno a las distintas dimensiones del cuidado a su definición como trabajo, remunerado y no remunerado, y al papel que en esa definición desempeñan la división sexual del trabajo, por un lado, y los circuitos de cuidado, por otro. Se trata de poner el foco en los cuidados como imperativo en el orden existente de la organización del mercado de trabajo y del funcionamiento de las sociedades actuales desde la perspectiva de la reproducción social.

A partir de ahí, y partiendo de lo social, se analizarán las tensiones que generan los nexos entre trabajo de cuidados no remunerado y trabajo remunerado en las mujeres. Estas tensiones se analizarán teniendo en cuenta los efectos de la organización social del cuidado, del funcionamiento de los distintos regímenes de cuidado, y de la interacción entre instituciones, familia y mercado, todo ello en el contexto de la actual crisis global de cuidados, y como punto de partida de un nuevo pacto social. 
Palabras Clave: Cuidados, género, organización social, trabajo no remunerado, reproducción social, políticas

\begin{abstract}
Starting with the analysis of the different terms which define caregiving, and taking into account the dual perspective of the "ethics of care", and the subsequent links with gender theory, we shall study the different dimensions of caregiving when defined as actual work, both paid and unpaid. On the one hand, we shall examine the role played by said definitions in the sexual division of labour, but also from the standpoint of care networks. The aim is to highlight not only the importance of caregiving within the existing labour market organisation, but to also underline the workings of current societies from a social reproduction standpoint.
\end{abstract}

Thus, and considering the social element, we shall study the tensions created by the connections between unpaid and paid caregiving amongst women. These tensions will be examined taking into account the effects of the social organisation of care, as well as the interaction between institutions, family and markets - all of them seen within the context of the current global caregiving crisis, and as a starting point for a new social pact.

KEYWORDS: Care, gender, social organization, unpaid work, social reproduction, politics

\title{
SUMARIO
}

\section{Introducción}

II. El concepto de cuidado

\section{El derecho a cuidar y a ser cuidado}

III. Regímenes y organización social del cuidado

IV. El trabajo de cuidados

1. Trabajo de cuidados no remunerado

2. Trabajo de cuidados remunerado

$V$. Algunas reflexiones finales

Bibliografía

\section{Introducción}

"Las tareas de atención y cuidado de la vida de las personas son un trabajo imprescindible para la reproducción social y el bienestar cotidiano. Un trabajo, que lejos de afectar sólo a las mujeres, resulta de vital importancia para toda la sociedad. Siendo así desde que el mundo existe (...) los intereses del mercado y la lógica del beneficio enmascaran esa realidad" (Carrasco, Borderías y Torns, 2011: 9). Esta idea es el punto de partida de este trabajo, que pretende comprender el trabajo de cuidados y su papel en las actuales estructuras económicas y laborales, a partir de las tensiones derivadas de su propia definición, de los distintos regímenes de funcionamiento y de su organización social. 
Como se verá más adelante, el marco teórico conceptual de la conciliación de los cuidados y de la corresponsabilidad ha travesado una evolución diferenciada, pasando de la conciliación en relación con los cuidados, como aquellas actividades necesarias para los que no pueden valerse por sí mismos, a la corresponsabilidad, entendida como responsabilidad compartida entre los agentes y los actores del sistema de cuidados. Pero antes de esta corresponsabilidad, quienes se hacen cargo del cuidado son las mujeres, y una vez se generaliza la actividad laboral femenina fuera del hogar, y la actividad laboral remunerada de las mujeres se configura como una nueva normalidad social, aparecen los problemas para atender las necesidades de cuidado, y es la familia, las mujeres de las familias en realidad, las que se encargan del mismo.

La provisión de cuidados es diaria (Batthyány, 2004) y puede tener distintas características, con distintas implicaciones: trabajo remunerado o no remunerado; sobre la base de un acuerdo o de forma voluntaria; y de forma profesional o basado en obligaciones morales. Hoy en día, a pesar de las distintas pautas laborales de hombres y mujeres, la magnitud tanto en la entrada como en la permanencia de las mujeres en el mercado de trabajo productivo ha cambiado, y se ha producido una aceleración del cambio social, dado que aún después de la maternidad, las mujeres se mantienen en el mercado de trabajo remunerado rompiendo con las pautas tradicionales, de manera que se ponen de manifiesto los problemas para atender esas necesidades diarias de cuidados, tanto si se realizan de manera más o menos informal, y tanto si son remuneradas como si no se remuneran.

Pero es que, además, han aparecido dos elementos clave en el análisis de los cuidados. Uno es el autocuidado como elemento de conciliación personal, y el otro es la conciliación con otros ámbitos de la vida, en relación con la exigencia de que el mundo de la actividad laboral debe reconocer que las personas trabajadoras tienen otros ámbitos vitales que el mundo del empleo debe respetar. Ahora bien, estas nuevas prácticas sociales no han venido acompañadas de nuevas políticas sociales adecuadas que puedan sustituir a la madre cuidadora a tiempo completo, de modo que se está generando un déficit de cuidados a nivel global.

\section{El concepto de cuidado}

Conviene recordar que "nadie puede sobrevivir sin ser cuidado, lo cual convierte al cuidado en una dimensión central del bienestar y del desarrollo humano" (Esquivel, Faur y Jelin, 2012:11). En sentido amplio, este cuidado encierra todas las "actividades de la especie que incluyen todo lo que hacemos para mantener, continuar y reparar el mundo en que vivimos (Tronto, 1993: 103). En un sentido más concreto, el cuidado comprende todas "las actividades y relaciones orientadas a alcanzar los requerimientos físicos y emocionales de niños y adultos dependientes, así como los marcos normativos, económicos y sociales dentro de los cuales éstas son asignadas y llevadas a cabo" (Daly y Lewis, 2000: 285). Como señalan Esquivel, Faur y Jelin (2012: 19), "el grado de autonomía o dependencia debe ser visto como un continuo: si bien se puede pensar en un 
extremo de dependencia casi absoluta, resulta difícil, si no imposible, imaginar una situación de autonomía absoluta". Es decir, dado que todos los seres humanos son vulnerables y frágiles (aunque algunas personas sean más vulnerables que otras, especialmente cuando son jóvenes, mayores o están enfermas), todas las personas a lo largo de su vida son susceptibles de ser cuidadas, a la vez que son susceptibles de proveer cuidados (Tronto, 2017).

Pero no siempre el concepto de cuidados ha sido este. Como señala Pineda (2019: 117), "la crítica feminista al mundo del trabajo presenta distintas fuentes disciplinarias y contribuciones conceptuales, que han llevado, en las últimas décadas al "giro conceptual del cuidado". Ahora bien, hay destacar que el concepto de cuidados puede no responder a las demandas de todos los colectivos implicados, es decir, de las personas que cuidan y las personas cuidadas, incluso en ocasiones las definiciones de cuidados pueden resultar contradictorias con esa dicotomía de persona cuidada y persona cuidadora.

Durante los años 60 no había una relación de conflicto entre el mundo doméstico familiar y el mundo de la actividad laboral, pero años más tarde empiezan a generarse tensiones en el modelo predominante. Así, en la década de los setenta, los análisis sobre el capitalismo y la división sexual del trabajo señalaban la distinción entre trabajo productivo y trabajo reproductivo, poniendo el foco en la invisibilidad del trabajo de las mujeres y su circunscripción a la esfera privada y no remunerada (Benería, 1979; Himmelweit, 1999), de forma tal que "el trabajo doméstico se considera un requisito del capitalismo (o de los varones que explotaban a sus mujeres), por lo que debía abolirse (Esquivel 2013: 24).

En la década de los noventa, la economía feminista anglosajona (base de la futura economía del cuidado) criticaba los circuitos económicos que sólo involucraban a los mercados, y que invisibilizaban el aporte económico del trabajo de las mujeres y los hogares como unidades productivas, y no solo como unidades de consumo (Folbre 1994, 1995; Elson, 1995). Por su parte, desde el feminismo norteamericano se estudiaron las características emocionales del trabajo de las mujeres y se acuñó la noción de ética del cuidado, especialmente en aquellas actividades ligadas al cuidado directo de las personas (Gilligan, 1982). A partir del año 2000, el foco de análisis pasa del trabajo al cuidado (Himmelweit, 2000), centrando la atención en los aspectos positivos del trabajo de cuidados, esto es, en los beneficios que produce en quienes lo reciben, y no tanto en los costes en que incurren las mujeres al proveerlo, en las tensiones que les generan y en las restricciones que se imponen sobre quienes lo proveen (Esquivel, 2013: 27).

Con la evolución de los estudios del cuidado se sitúa el concepto fuera del ámbito de los hogares y se ubica en el centro de la organización social (Tronto, 2013), poniendo de manifiesto que las tareas que se producen en el ámbito doméstico son imprescindibles para el funcionamiento económico, político y social, y por ello es necesario pensar sobre cómo valoramos el cuidado y sobre cuál es su relación con la política (Tronto, 1993). Pero, aún hoy, no hay un acuerdo sobre la definición del cuidado, lo que genera fronteras versátiles y frágiles en su definición, y problemas de delimitación, de cara, por ejemplo, a su análisis empírico y a las propuestas legislativas o presupuestarias, entre otras. Y para 
visibilizar el cuidado es prioritario poder identificar el fenómeno, establecer cuáles son las categorías sociales que lo componen, y a partir de ahí, diseñar políticas públicas que lo acompañen.

En este sentido, básicamente existen dos recorridos conceptuales principales. El primer recorrido es el recorrido anglosajón, que aparece en los años 70 y 80 y que parte de la discusión del cuidado materno para llegar a la discusión del cuidado social. Autoras como Graham (1983) analizan el cuidado como el trabajo de las mujeres en el marco de la familia y parten de la idea de que las tareas de cuidado materializadas en trabajos remunerados no son cuidados, sino una mera prestación de servicios, servicios sustitutivos del cuidado. Y no son cuidado porque falta el compromiso de afecto que transforma el cuidado de tarea en deber; al tratarse de servicios de cuidado que se realizan fuera del ámbito familiar, no se realizan con la virtud de afecto que caracteriza el cuidado.

Por otro lado, Gilligan (1985) analiza el distinto modo en qué se comportan hombres y mujeres respecto a los cuidados. Para los hombres, este comportamiento se basa en establecer derechos y principios elementales, iguales para todos y todas, que no tienen en cuenta las situaciones personales, sino que se guían por la lógica de la justicia y el deber moral. En cambio, para las mujeres, lo más importante es precisamente el vínculo personal más allá de las necesidades sociales generalizadas. Dado que la clave es ese vínculo personal en los cuidados, son las mujeres las que realizan este trabajo de cuidados. En resumen, "se trata de un modelo ético basado en la responsabilidad hacia los demás que subyace a la actitud femenina, generalmente receptiva hacia las necesidades de las personas con las que se relacionan. El modelo moral masculino se basa más bien, según Gillingan (1985), en la noción de derechos del individuo, de uno mismo, frente a una hipotética justicia imparcial" (Tobío, 2012: 405). Pero existen otras conceptualizaciones feministas frontalmente opuestas a la asociación naturalizada de la mujer al cuidado, como la de Anderson (2008): el aspecto afectivo de los cuidados no debe subordinarse al aspecto material, del trabajo que tienen los cuidados y, por tanto, deben poder realizarse en el marco de la familia, pero también en el marco de otras instituciones. Es decir, las relaciones de cuidado pueden estar mediadas por relaciones económicas y de trabajo, o no, y pueden existir diferentes dotaciones de afecto y de trabajo, independientemente de si existe una remuneración o no.

A diferencia del recorrido anglosajón, centrado en el amor- afecto, el recorrido latinoamericano tiene su punto de partida en los análisis del trabajo propiamente dicho y especialmente en los análisis sobre la división sexual del trabajo. Por tanto, en el recorrido latinoamericano, la clave está en el ámbito reproductivo, en lo que se hace en el ámbito doméstico para reproducir la vida cotidiana, en todas las tareas que se hacen en el ámbito reproductivo del hogar (producción de bienes materiales, provisión de afectos y cuidados directos de menores y mayores, etc.), y en el vínculo de este ámbito reproductivo del hogar con el ámbito productivo fuera del hogar. Este vínculo está caracterizado por la invisibilidad del ámbito reproductivo doméstico, y es la formas de trasladar los costes de la esfera productiva a la esfera doméstica, que es donde se mantiene la fuerza de trabajo que se traslada al ámbito productivo fuera del hogar. Esta esfera del ámbito reproductivo 
doméstico, no remunerada y altamente feminizada, determina la participación de las mujeres en el mercado de trabajo fuera del hogar, como se verá más adelante.

Pero "pese a su amplio uso, el concepto de cuidados es ambiguo y también discutido. Parte del problema reside en que sea utilizado de forma tan distintas que corre el riesgo de perder su significado central. (...) Como categoría general de análisis preferida del Estado de bienestar es preciso encontrar la manera de conservar su capacidad para desvelar dimensiones importantes de la vida de las mujeres (...) y captar al mismo tiempo las características más generales de los dispositivos sociales establecidos en relación con las necesidades y el bienestar personales" (Daly y Lewis, 2011: 230). Para este objetivo, la idea de social care o cuidado social saca el cuidado de la esfera familiar y comienza a ser la clave para analizar los regímenes de bienestar de manera pluridimensional y transversal, y se define como "el conjunto de las actividades y las relaciones que intervienen en la satisfacción de las necesidades físicas y emocionales de las personas adultas dependientes y de las niñas y niños, y los marcos normativos, económicos y sociales en los que aquellas se asignan y se desarrollan" (Daly y Lewis, 2011:231).

Este cuidado social tiene tres dimensiones: la primera, es la de los cuidados como trabajo, lo que lleva a reflexionar sobre la naturaleza del trabajo y su comparación con otras formas de trabajo, así como las condiciones en las que se lleva a cabo este trabajo de cuidados; la segunda dimensión se centra en el marco normativo de obligaciones y responsabilidades sociales y/o familiares, proporcionando al Estado un papel clave con relación a los cuidados; la tercera y última dimensión se refiere a los costes de la actividad de cuidados, tanto costes financieros como emocionales, y tanto costes públicos como costes privados.

Un aspecto importante del cuidado social es su análisis macro con relación a las infraestructuras de cuidados, pero también en relación con la financiación y los servicios. Como señalan Daly y Lewis (2011:233) al analizar este cuidado social, "no nos centramos en los servicios sociales de cuidados sino más bien en la relación entre (la existencia y el carácter de) dichos servicios y las prestaciones monetarias en Estados de Bienestar concretos. Un segundo aspecto analítico en el plano macro se refiere a la economía política de su prestación por los diferentes sectores y entre éstos. La división del trabajo, la responsabilidad de los costes de los cuidados entre la familia, el mercado, el Estado y los sectores de voluntariado comunitarios es el punto de partida analítico fundamental en este caso".

En este sentido la provisión de los cuidados tiene fronteras variables tanto a escala macro como escala micro. "A escala macro, los cambios pueden identificarse en forma de desplazamientos en la distribución de los cuidados entre los distintos sectores. A escala micro, las trayectorias de cambio abarcan la distribución de los cuidados entre las personas individuales y entre las familias, así como la modificación de las condiciones bajo las cuales se prestan y se reciben cuidados" (Daly y Lewis, 2011:235)

Según Tobío (2008), el punto fuerte del cuidado social es que establece el cuidado como actividad más allá de los contextos particulares, y pone el foco en la interacción entre 
familia, estado y mercado, es decir, en cómo se reparten las tareas y las responsabilidades de cuidado entre estas tres instituciones y cómo es la combinación de sus recursos, incluyendo no sólo la infraestructura material para el cuidado, sino también la dimensión normativa en forma de obligaciones, responsabilidades y valores. El cuidado social liga el trabajo de cuidado con los distintos regímenes de bienestar y las políticas sociales, es decir, vincula obligaciones, costes y responsabilidades a los distintos actores del cuidado, e involucra todas las relaciones sociales, políticas y económicas que intervienen en la satisfacción de las necesidades de cuidados, determinando además cómo los marcos normativos y económicos favorecen o no la satisfacción de esas necesidades.

Esto es, con el concepto de cuidado social, "el cuidado se interpreta como una relación (...) y, asimismo, como una responsabilidad socialmente construida (...) que tiene lugar dentro de determinados contextos sociales y económicos" (Esquivel, 2013: 8), dado que se enfocan los cuidados desde un punto de vista macro, al involucrar al estado, al mercado y a la sociedad, al centrar el análisis en cómo se provee y se distribuye el bienestar en cada sociedad, colocando a los cuidados como un componente principal de ese bienestar. De este modo se desplaza el debate del cuidado por amor de los años ochenta y se coloca el estudio de los cuidados en la política.

A partir de la teoría del cuidado social se da visibilidad al trabajo doméstico y de cuidados realizado por las mujeres, trabajo en muchas ocasiones no reconocido porque se conceptualizaba como biológicamente correspondiente a la mujer. Pero en el cuidado social convergen aspecto privados (como las preferencias, las decisiones y los recursos disponibles) con elementos sociales (como el mercado de trabajo y las políticas familiares, entre otros). Y ambas dimensiones, público y privada, están interconectadas y son interdependientes (Elizalde-San Miguel, 2018). El reconocimiento que el trabajo de cuidados tiene en el bienestar social pone de manifiesto todos los actores del cuidado, a saber, familias y sociedad, Estado y mercado son claves para la organización social del cuidado hoy.

Desde las distintas aportaciones y reflexiones sobre el concepto de cuidados se ha generado un concepto multidimensional e interdisciplinario, al que autoras como Arango (2015) suman el énfasis del cuidado como trabajo porque "el cuidado es, ante todo, un conjunto de actividades físicas y emocionales que se deben realizar para atender necesidades y brindar bienestar a otras personas" (Pineda, 2019: 118). En este sentido, una de las claves del estudio del trabajo de cuidados es cómo caracterizar sus actividades. Según la ONU Mujeres (2014: 11), para entender mejor de qué hablamos cuando hablamos de cuidados se pueden distinguir sus contenidos en cuidados directos, precondiciones del cuidado y gestión mental: los cuidados directos se refieren a las tareas que implican la interacción directa de las personas para lograr salud física y emocional; las precondiciones del cuidado se refieren a las tareas que establecen las condiciones materiales que hacen posibles los cuidados directos (trabajo doméstico), y la gestión mental se refiere a las tareas de coordinación, planificación y supervisión. Ahora bien, como recuerda Batthyány (2015: 10), "la naturaleza de la actividad variará según se 
realice o no dentro de la familia y, también, de acuerdo a si se trata o no de una tarea remunerada".

Pero el cuidado, además de comprender una serie de actuaciones, incluye una serie de disposiciones (Tronto, 1993) y está dirigido a aquellos que necesitan una ayuda extra, como niños o mayores, pero es mucho más que eso, dado que tiene distintos ángulos desde los que aproximarse: incluye también el cuidado de objetos, el autocuidado, el cuidado del medio ambiente, de las infraestructuras. Siguiendo esta idea, se concibe el cuidado es una actividad de la espacie (Fisher y Tronto, 1990) y está en todas partes. Es todo aquel que hacemos para reparar, mantener y continuar nuestro mundo, para que lo podamos habitar de la mejor manera posible. Incluye nuestro cuerpo, nuestro ser y nuestro ambiente. Es todo lo que buscamos entretejer en una compleja red que sostiene la vida.

Según Fisher y Tronto (1990), este cuidado tiene cuatro fases con las que pueden analizar sus procesos: (a) El cuidado que importa: se trata de reconocer e identificar algo o alguien que necesita cuidado; (b) Cuidar a: una vez identificadas las necesidades, se requiere que alguien asuma la responsabilidad de llevar a cabo ese trabajo de cuidado; (c) Dar cuidado: es el trabajo de proveer cuidado; y (d) Recibir cuidado: implica analizar lo que ha pasado después de durante el proceso de cuidado y a su término. Y todas estas fases requieren de una cualidad moral. Un cuidado que importa requiere de forma moral ser atentos. "Cuidar a" requiere pensar bien en la naturaleza de la responsabilidad; dar cuidado requiere de la cualidad moral de la competencia y recibir cuidado requiere de la reciprocidad. Estas cualidades no son unidireccionales, sino que el cuidado y todos sus aspectos van en todas las direcciones. Es decir, existe una quinta fase del cuidado que requiere de nuevas cualidades morales (Tronto, 2013).

Las necesidades de cuidado se reiteran constantemente y al reiterarse, se crean las condiciones para que las personas anticipen que sus necesidades van a ser atendidas por otros. En esta quinta fase del cuidado, la de "cuidar con" se requiere de la confianza hacia el cuidador y la solidaridad con las personas con las que formamos relaciones de cuidado. Es decir, el cuidado no es sólo un sentimiento o una disposición, ni una serie de acciones, sino un mecanismo complejo de prácticas, con un aspecto relacional clave, que asume que la gente, estando con otros y con el medio, es interdependiente, y, por tanto, conceptualmente, la responsabilidad del cuidado es un acto colectivo (Tronto (2015). Porque "el cuidado es entendido como trabajo y relación interpersonal, pero también como responsabilidad socialmente construida que se inscribe en contextos sociales y económicos particulares" (Batthyány, 2015:10).

Ahora bien, resulta difícil determinar dónde acaba el cuidado y dónde empieza algo diferente. Hay muchas actividades de cuidado dentro de otras actividades, de cuidado o no, actividades que pertenecen al cuidado y se combinan para formar actividades mayores del cuidado. Por otro lado, la persona que recibe cuidados hoy puede ser la que los dé mañana, de manera que los cuidados están cambiando constantemente, moviéndose de una persona a otra. Pero es que, además, "recibir cuidados no es lo opuesto a la independencia o a la realización personal (...), no se trataría de dependencia e 
independencia, sino, más bien, de "interdependencia", lo que caracteriza la condición humanan (Esquivel, 2013:29).

Según Batthyány (2004) existen tres tipos de actividades de cuidado: (a) el trabajo productivo, social, colectivo, que genera riqueza social; en línea con la organización social del trabajo según las condiciones históricas de cada sociedad, y los distintos modos de producción establecidos; (b) el trabajo doméstico, individual, para satisfacer necesidades de la vida cotidiana: alimentación, salud, higiene, vivienda; y (c) la crianza: transmisión de usos y costumbres de la comunidad, garantizando la reproducción del imaginario social y cultural. Pero existe una cuestión clave que atraviesa todas las anteriores: la situación relacional, con distintas formas, entre quien cuida y quien es cuidado. Porque "el cuidado es más que atención, más que una tarea. Implica trabajo emocional y relación. Es pasivo además de activo” (Lewis, 2011: 349).

En este sentido conviene prestar atención a cómo hombres y mujeres experimentan de manera distinta el mandato de cuidar y cómo la expectativa de que las mujeres cuidarán debilita su poder negociador en el hogar y en el mercado de trabajo, y que incluso cuando se mercantilizan los cuidados, éstos nunca sustituyen plenamente al trabajo de cuidados no remunerado, ni elimina la necesidad de recurrir al cuidado informal prestado por familiares y amistades. Es decir, "el trabajo de cuidados se tiene que hacer y, por lo tanto, es un lugar central en la elaboración de políticas (...) y tiene que existir la posibilidad de elegir hacerlo (Lewis, 2011: 350).

\section{El derecho a cuidar $y$ a ser cuidado}

Parece evidente la necesidad de desarrollar una nueva perspectiva de los cuidados y las responsabilidades domésticas, dado su valor social y su carácter constitutivo de la ciudadanía social. En este sentido, se trata de desprivatizar el cuidado, de sacarlo de la esfera privada y reconocerlo como público, de manera que el elemento central dejar de a los cuidados como un problema individual para comenzar a tratarlo como un problema colectivo, social y que por ello requiere de respuestas colectivas. Además, "el carácter doméstico de los cuidados es la base para su exclusión de los derechos ciudadanos; lo que está faltando es un concepto de ciudadanía que reconozca la importancia de los cuidados y las responsabilidades domésticas para la sociedad. El limitar las responsabilidades de los cuidados casi exclusivamente a la esfera privada, convirtiéndolo en un problema privado, torna muy dificultoso el convertirlo en un objeto de derecho real" (Fraser (1997) en Batthyány, 2004: 54).

Por eso, como señalan Aguirre et al. (2014: 51), "recientemente se ha enfatizado en la dimensión de los cuidados como un derecho, lo que modifica el concepto de ciudadanía (...). Esto conlleva que el Estado garantiza el derecho a recibir cuidados en distintas circunstancias y momentos del ciclo vital y evita que la satisfacción de esa necesidad se determine por la lógica del mercado, la disponibilidad de ingresos o por la presencia de redes vinculares".

Considerar el cuidado como un derecho implica una nueva concepción de la relación entre individuo, familia y Estado "basada en la responsabilidad compartida de los cuidados de 
las personas" (Aguirre et al. 2014: 51). El cuidado se concibe como un derecho universal desde la doble perspectiva de quienes precisan cuidados y quienes cuidan, es decir, desde la doble perspectiva del derecho a dar (o no) cuidados (esto es, el derecho a elegir si se quiere o no cuidar) y el derecho a recibir cuidados (Batthyány, 2015). Se trata pues de un derecho para toda la ciudadanía, como fundamento para el bienestar de la vida cotidiana, lo que implica reflexionar sobre las condiciones en las que se realiza el trabajo de cuidados, tanto si es remunerado como si no lo es, de manera que se reconozca su valor económico y social.

El derecho a recibir cuidado a lo largo de todo el ciclo vital debe estar garantizado, independientemente de la posición social o económica (y las posibilidades que esta posición genere para comprar servicios de cuidado en el mercado) y de la densidad familiar o comunitaria. En cuanto al derecho a dar cuidado, deben existir mecanismos que lo garanticen, independientemente de la existencia o ausencia de mujeres en las relaciones familiares, porque "el cuidado es un derecho de todos y todas y debe garantizarse por medio de arreglos institucionales y presupuestarios, ser normado y obtener apoyo estatal. No es, por tanto, un beneficio para las mujeres y sí un derecho de quienes lo requieren" (Pautassi (2010) en Batthyány (2015: 12). El punto central es que el cuidado no es una responsabilidad individual, sino colectiva, y por tanto deben existir mecanismos y colectivos de apoyo y respuestas colectivas garantizadas como sociedad, a través del Estado y las políticas púbicas a través de intervenciones transversales. El cuidado como derecho que implica el derecho a cuidar, el derecho a ser cuidado y el derecho al autocuidado, es un reconocimiento para las personas y una obligación para el Estado, que debe garantizar su efectivo ejercicio, mediante tiempos para cuidar, provisión de infraestructuras y mediante la implementación de un sistema de transferencias monetarias (Pautassi, 2018).

Ahora bien, dado que el Estado aún delega el cuidado en las familias, se produce una distribución no equitativa de los cuidados dentro de las mismas, puesto que son las mujeres las que los asumen mayoritariamente. Sobre este particular, Pautassi (2007) recuerda que, a pesar de los avances que se han producido en la igualdad en distintos ámbitos (públicos), se han perpetuado y reproducido las desigualdades en el ámbito doméstico (privado), de modo que la desigualdad ha atrapado a las mujeres entre responsabilidades productivas y reproductivas. Por consiguiente, el Estado debe proveer de responsabilidad de cuidados al hombre, a través de transformaciones y nuevas relaciones de la vida cotidiana, puesto que el cuidado es un derecho de las personas, y, por tanto, no se trata de dar apoyo a las mujeres que trabajan o quieren trabajar, sino de garantizarlo tanto institucionalmente como presupuestariamente. Pero la garantía de la igualdad no debe implicar un trato igualitario a quienes se encuentran en distintas circunstancias: cuidador y receptor del cuidado no están en igualdad de condiciones, dadas las estructuras asimétricas de unos sobre otros, es decir, dada la existencia de cadenas de desigualdad en el cuidado.

En cuanto a la regulación jurídica del cuidado, el debate es cómo incorporar en una lógica de derechos la complejidad del cuidado, en cuanto al estatus de trabajador asalariado, del 
sujeto beneficiario de las políticas del cuidado y en relación con la igualdad de trato, de oportunidades y de trayectoria laboral. Y esta complejidad del cuidado tiene que ver con su carácter polisémico (en cuanto a que se dan al inicio y al final de la vida, pero durante toda la vida también), sus dinámicas de organización social y sus efectos sobre la reproducción de la vida cotidiana y la fuerza de trabajo.

Por todo ello, el derecho al cuidado como derecho universal tiene que reflexionar sobre quiénes deben ser cuidados y quiénes deben o quieren cuidar, como obligación pública o privada y sobre quiénes son los sujetos obligados a prestar el cuidado, además de reconocer la contribución invisible de las mujeres a la economía a través de cuidado, priorizando el valor de la reproducción social, con políticas y prácticas equitativas.

\section{Regímenes y organización social del cuidado}

Hasta hoy, las necesidades de cuidado han sido cubiertas. Dado que lo han asumido las mujeres, esa seguridad de que el cuidado iba a estar garantizado ha retrasado la asunción colectiva del mismo (Batthyány, 2015). Pero hoy el cuidado se ha convertido en una cuestión social urgente por dos motivos principales: los cambios demográficos (las mujeres cuidan hijos, pero también cuidan mayores), y el proceso emancipatorio de las mujeres: ahora, además de cuidadoras, son ciudadanas, trabajadoras, militantes, y participan en lo público y en el proceso de adquisición de derechos.

Como señala Batthyány (2015:11), "parte importante del problema (...) radica en una adecuada distribución de esas responsabilidades que entre sus distintos miembros", porque, en relación con el bienestar social, son las familias (las mujeres de las familias en realidad) las que ajustan sus funciones para garantizar ese bienestar social. Y ese ajuste se realiza a través de su actividad laboral, sus horas dedicadas al trabajo remunerado, sus horarios, sus jornadas o incluso su propia participación en el mercado de trabajo. A este respecto, Pautassi (2007) recuerda que los componentes del cuidado se refieren a la disponibilidad de tiempo, dinero y servicios. Según se estructuren estos tres elementos, así serán los modelos de provisión de cuidado y las dinámicas de los hogares. En la configuración de esta estructura, el papel del Estado no es neutral, dado que "distintos regímenes de bienestar se asociarán así a distintos regímenes de cuidado, de acuerdo con los modos en los que se asignan las responsabilidades de cuidado y se distribuyen los costos de proveerlo" (Batthyány, 2015:11).

A este respecto, hay que señalar que el cuidado ha sido atendido desde dos ópticas: por un lado, la óptica normativa y las políticas para organizar el cuidado en los hogares a la vez que las mujeres, que son las que organizan ese cuidado, se inserten el empleo remunerado, y, por otro lado, la óptica de las políticas sociales, asistenciales en muchos casos, ligados los menores y mayores dependientes. "Esto es, se lo considera "vinculado con" o en "relación a" pero no ocurre, salvo excepciones, un tratamiento del tema de manera autónoma y en toda su amplitud y complejidad" (Pautassi, 2007: 10). Para este fin, y siguiendo a Ravazi (2007), "el concepto de regímenes de cuidado puede utilizarse para establecer la tipología de varios tipos de Estados benefactores, de acuerdo con las 
formas en que las responsabilidades del cuidado se asignan y se asumen los costos de su provisión" (Esquivel 2013: 8). Por ese motivo, conviene tener en consideración dónde se presta el cuidado (hogares, instituciones públicas), quién cuida (familias, padres, madres, trabajadoras del cuidado) y quién paga los costes de proveer dicho cuidado (transferencias, provisión pública de servicios, empleadores, familias).

Por otro lado, las dos dimensiones del cuidado, la pública y la privada, están interconectadas y son interdependientes, y todos ellos son claves para la organización social del cuidado hoy (Elizalde-San Miguel, 2018). Pero buena parte de estos elementos sociales no son "neutros" para la igualdad efectiva entre hombre y mujeres. En este sentido, Fraser (1997) establece varios modelos de cuidados, entre los que se encuentran el modelo de paridad de cuidado y el modelo de integración. En el modelo de paridad de cuidado, se reconoce y acepta la diversidad de tareas según género, pero se igualan los derechos asociados. Es decir, se asegura que quienes cuidan, las mujeres, no están penalizadas, equiparando derechos sociales y económicos del trabajo de cuidados con otros trabajos en el mercado laboral, asegurando además "el derecho a cuidar de quienes optan por encargarse directamente de sus familiares" (Tobío, 2019: 167). En el modelo de integración, se reconoce el derecho a cuidar y a trabajar en el mercado de hombres y mujeres, junto con la obligación derivada de este derecho, a saber, hombres y mujeres deben asumir ambas tareas a lo largo de la vida. Se trata de un modelo igualitario en tareas laborales y tareas de cuidado, pero también en el reconocimiento de derechos individuales. Este modelo exige un aparato social público potente para poder sostenerse, con la igualdad de género como eje de actuación.

A partir de los recursos disponibles en cada país, Leitner (2003) establece cuatro modelos de análisis. Estos modelos, según Elizalde, Díaz y Díaz (2015: 124-125) pueden resumirse como sigue: (1). Familismo opcional: da a las familias la posibilidad de elegir la estrategia de cuidado que creen más oportuna, garantizando tanto disponer de tiempo para cuidar en primera persona como el desarrollo de una amplia cobertura de servicios públicos (escuelas infantiles, fundamentalmente) para delegar el cuidado si ésta es la opción elegida. (2). Familismo explícito: corresponde a los sistemas que fomentan la asunción del cuidado dentro de la familia y, consecuentemente, centran sus recursos en prolongados permisos laborales. El modelo tiende a reproducir relaciones de género tradicionales, puesto que existe una inercia a que la mujer sea quien asume estos permisos. (3). Familismo implícito: es aquel que entiende que las familias son las responsables de cuidar, pero no les reconoce ningún derecho específico ni les facilita servicios alternativos. Es el modelo que más perpetúa la tradicional división sexual del trabajo, ya que el cuidado acaba recayendo en las mujeres, que tienen más dificultades para entrar o mantenerse en el mercado laboral. (4). Sistemas desfamiliarizados: se caracterizan por no garantizar el derecho de las familias a cuidar. Los permisos parentales son reducidos y la desfamiliarización se produce a través del Estado, mediante servicios públicos, o el mercado, con la contratación de cuidadores particulares. Según Pautassi (2007: 13), lo que está ocurriendo hoy es un "acelerado proceso de desfamiliarización como condición previa a la capacidad de mercantilización por parte de las mujeres, esto, es, la 
desfamiliarización implicaría el grado en que la política social o los mercado, otorgan autonomía a las mujeres para poder mercantilizarse o para establecer núcleos familiares independientes".

A este respecto, "el concepto de organización social y política del cuidado nos permite reconocer una estructuración heterogénea y dinámica (...) en la cual intervienen a la vez la oferta de servicios y su demanda" (Faur y Pereyra, 2018: 499). Es decir, la organización social del cuidado, entendida como la "configuración dinámica de los servicios de cuidados suministrados por diferentes instituciones, y a la forma en que los hogares y sus miembros se benefician de ellos" (Faur, 2011: 969), es la que sustenta el funcionamiento económico y social, e implica la distribución de responsabilidades y tareas entre familias, estado, mercado y comunidad.

Además, en la actualidad la organización social del cuidado está en crisis debido a factores como los cambios demográficos, las transformaciones familiares $\mathrm{y}$, sobre todo, la cada vez mayor autonomía económica de las mujeres derivada de su mayor participación laboral. Esto genera que esa organización social del cuidado, así como las demandas y necesidades de cuidado, hasta ahora en manos de las mujeres, empiecen a no estar garantizadas. "Existe un déficit de cuidado que (...) tiene carácter estructural desde el fin de la especialización de género, cuando las mujeres se incorporaron de manera generalizada al mercado de trabajo y, especialmente, desde que las madres que trabajan constituyen una nueva normalidad social (Tobío, 2005). La actividad femenina en el cuidado de las personas no ha sido sustituida, más que de manera muy parcial, por otras formas de atención en las que el conjunto de la sociedad, más allá de la familia, asume tal responsabilidad. Esta tarea no ha sido asumida íntegramente por el Estado en ningún país y la problemática de la compatibilidad entre vida laboral y vida familiar ha pasado a ocupar un papel central" (Fernández y Tobío, 2019: 100).

El reto es garantizar el cuidado y el derecho al cuidado, avalando a su vez la autonomía y el bienestar de las familias y los individuos, por lo que la competencia del Estado es fundamental y debe avanzar hacia la inclusión positiva y el reconocimiento del cuidado en las políticas públicas, lo que implica trabajar en tres ámbitos: redistribuir, revalorizar y reformular los cuidados (Pérez y Gil, 2011). Como recuerda Batthyány (2015: 17), "significa construir una responsabilidad colectiva en torno a los cuidados, transitar de su consideración exclusivamente privada a considerarlo un tema de responsabilidad colectiva y, por tanto, lograr el acceso universal a cuidados dignos. Revalorizar implica dignificar los cuidados como trabajo y reconocerlos como una dimensión esencial del bienestar. Reformular remite a desanudar los cuidados de su asociación con la feminidad y la familia exclusivamente". Así pues, las políticas que concilian vida familiar y laboral deben reasignar tiempo, ingresos y servicios, de manera que permitan alternar los tiempos dedicados al trabajo productivo con los tiempos destinados al trabajo de cuidados dentro de la familia, o bien transferir los cuidados a servicios con alguna participación estatal, o bien mercantilizar parte de estos servicios de cuidados a través de la contratación privada por parte de las familias, transformando el domicilio en lugar de trabajo. 
Estos tres tipos de políticas secuenciales (protección de los ingresos), desfamiliaristas (provisión de servicios) y regulatorias (contratación de trabajo de cuidados) son distintas y complementaria, y en todas ellas el estado puede intervenir, o no (Blofield y Martínez, 2014). En todo caso se requiere urgentemente una decidida acción política, dado que "la llamada crisis del cuidado no es otra cosa que un síntoma de la emancipación de las mujeres" (Montaño, 2010: 26), situación que va a revertirse, y que previsiblemente seguirá avanzando. Por esta razón, "la actual situación representa tanto un reto como una oportunidad (...). Mediante políticas públicas adecuadas, los gobiernos podrían interrumpir el actual círculo de reproducción de la desigualdad, así como promover un desarrollo social y económico más inclusivo (...). Por el contrario, de no mediar respuestas adecuadas a las tensiones entre la vida familiar y laboral, pueden profundizarse las desigualdades socioeconómicas y de género" (Blofield y Martínez, 2014: 108).

\section{EI trabajo de cuidados}

Como se ha puesto de manifiesto, el cuidado tiene tres dimensiones (material, económica y psicológica, afectiva, emotiva), dos formas (remunerado y no remunerado) y existen dos lugares de realización (dentro y fuera de los hogares). Las tareas de cuidado, tanto directo como indirecto, son parte de esa organización social del cuidado y pueden ser realizadas en distintos ámbitos y por distintas personas, pero normalmente requiere la combinación de trabajo remunerado y de trabajo no remunerado (Jelin, 2010), si bien su carácter remunerado o no remunerado no depende de su naturaleza, sino de elecciones políticas y de estructuras de género, como recuerdan Marco y Rico (2013). Además, no cabe duda de que el cuidado es una actividad feminizada, ya que son las mujeres las que, en todo el mundo, la llevan a cabo. Esto es así debido a la división sexual del trabajo aún imperante, lo que genera una inserción diferenciada y desigual de mujeres y hombres en el ámbito de lo público y lo social, basada en la diferencia entre el trabajo remunerado y el trabajo no remunerado, y la distinta participación de hombre y mujeres en cada uno de ellos.

Según la economía de los cuidados, los cuidados se encuentran en la base del funcionamiento y la reproducción económica y social. "El trabajo doméstico y de cuidado no remunerado produce valor (y, por consiguiente, puede considerarse productivo o económico) pero es invisible a los cálculos estándar del producto total" (Esquivel, 2013: 8). La economía de los cuidados asume que los cuidados son economía porque, por un lado, permiten reproducir la mano de obra de la economía mercantil, y, por otro lado, porque satisfacen necesidades de las personas, precisando para ello de recursos y trabajo.

Es decir, como recuerda Pautassi (2007: 10), "esta nueva disciplina nuclea al conjunto de las actividades socialmente útiles que no son monetariamente remuneradas, pero también crea bienes y servicios para el consumo directo de los miembros del hogar". Así pues, la economía de los cuidados cambia el enfoque tradicional, poniendo el centro no sólo en lo que sucede en los mercados, sino también en lo que sucede en los hogares, y alertando de que los trabajadores y las trabajadoras no son autosuficientes en relación con los cuidados, 
lo que interfiere directamente con su participación en el mercado de trabajo productivo (ONU Mujeres, 2014), y en este sentido, el nudo crítico es la injusta distribución del trabajo remunerado y las responsabilidades del cuidado, distribución injusta que además es el círculo reproductivo de la desigualdad (Rico, 2014).

\section{Trabajo de cuidados no remunerado}

En la actualidad las mujeres trabajan dentro y fuera de los hogares, pero "la presencia de las mujeres en el mercado de trabajo está muy condicionada por su situación familiar, lo que no ocurre en el caso de los hombres" (Fernández y Tobío, 2019: 102). Además, "la familia no solo condiciona el nivel de participación de las mujeres en el mercado de trabajo, también influye en la intensidad de esta participación" (Fernández y Tobío, 2019: 104).

Para Pautassi (2018), la incorporación de la mujer al mercado de trabajo reduce su tiempo disponible, tensionando las dinámicas de los hogares y visibilizando lo invisible, lo que hasta este momento estaba resuelto. Porque hoy en día aun "vivimos una situación de transición entre un viejo modelo de mujer y de familia caracterizado por una acusada división de roles de género y un nuevo modelo basado en la incorporación laboral de las mujeres. Sin embargo (...) no ha sido todavía reconocido y asumido (...) como un cambio y un problema social que obliga a redefinir formas de organización social desde la escala micro (la vida familiar) hasta la escala macro (las políticas sociales, el trabajo, el tiempo y el espacio" (Tobío, 2003: 42).

Al mismo tiempo, señala Faur (2014: 55), "las decisiones sobre la organización del cuidado se relacionan estrechamente con el trabajo femenino y con el esfuerzo por parte de las mujeres para conciliar responsabilidades con respecto a sus tiempos de dedicación a la familia y a la participación laboral". En consecuencia, esta nueva posición económica y social de las mujeres no está acompasada de los cambios necesarios en la organización social y familiar, de modo que se genera una "contradicción entre el nuevo rol laboral de las mujeres y la resistencia del contexto social a transformarse de acuerdo con la nueva situación (...). Esta contradicción la están resolviendo hoy las propias mujeres que la encarnan (...) a través de una variedad de estrategias" (Tobío, 2002: 158).

Estas estrategias son auténticos planes de acción, con un objetivo concreto y que están perfectamente diseñadas con criterios de racionalidad, cálculo y elección para poder resolver la vida familiar y laboral de los hogares, combinando lo individual con lo social, dentro de las posibilidades de elección, posibilidades que están determinadas por la estructura social del contexto. En esta línea, Faur (2014: 57) recuerda que "las mujeres realizan elecciones, pero (...) lo hacen dentro de determinadas bases- materiales y normativas- que constriñen los contextos en los cuales desarrollan sus vidas".

Conviene recordar como hace Batthyány (2015: 9) que "en contraposición al trabajo productivo, el trabajo doméstico debe llevarse a cabo todos los días a lo largo de la vida de una persona. Si hay personas que no lo realizan (...) otros lo hacen por ellas". Esto se traduce en que el trabajo de cuidados se realiza todos los años, todos los días del año, todas las horas del día, por lo que resulta imprescindible tener estrategias familiares muy 
bien diseñadas para poder compaginarlo con el trabajo productivo, especialmente en el caso de las mujeres, que son sobre las que las que mayoritariamente descansa tanto la gestión como la ejecución de los cuidados. Pero no hay que olvidar que esta flexibilidad adaptativa de las mujeres se deriva del hecho de que "el trabajo no remunerado de las mujeres es considerado, implícitamente, como flexible, susceptible de adaptarse y modificarse para compensar cualquier otro déficit de los recursos disponibles para la reproducción y mantenimiento de los recursos humanos (Aguirre y Fassler (1997) en Batthyány, 2004: 53).

En este sentido, Tobío (2002) establece que las estrategias de las mujeres para sortear las contradicciones familia- empleo pueden clasificarse en cuatro grandes categorías: principales, complementarias, extremas y directas. Las estrategias principales son las que son suficientes para responder a la totalidad de demandas del hogar y la familia; generalmente es la abuela materna la que cubre esta demanda, sustituyendo el papel de la mujer, o bien es una persona ajena a la familia (generalmente otra mujer), quien, a cambio de una remuneración, realiza estas tareas. Las estrategias complementarias son las que no son suficientes para cubrir las demandas del hogar, pero que se combinan con otras estrategias para lograr hacer compatible familia y empleo y cubrir estas necesidades domésticas; estas estrategias se traducen en soluciones dispares, como el uso de centros escolares o la reducción de las distancias para optimizar el uso del tiempo. Las estrategias extremas son las que resultan indeseables, y aparecen cuando no hay otra opción, como el hecho de tener que llevar a los hijos al trabajo o no ir a trabajar cuando están enfermos. Por último, las estrategias indirectas son las que se traducen en eliminar esa contradicción, eligiendo entre familia o empleo remunerado.

Ahora bien, como señala Tobío (2003: 45), las mujeres que trabajan todavía hoy superponen las viejas responsabilidades familiares a las nuevas responsabilidades laborales, pero a través de soluciones de urgencia provisionales y en muchas ocasiones las únicas posibles, porque a la hora de conciliar familia y trabajo el reparto entre el mercado, la familia y las políticas sociales acusa graves desequilibrios. Porque "ni siquiera cuando la intervención del Estado a través de políticas sociales es más activa se cubren todas las necesidades que el cuidado de las personas exige, sino que las mujeres, como responsables habituales de estas cuestiones tienen que combinar recursos formales e informales para dar respuesta a cada caso concreto" (Tobío, 2013: 31-32). Asimismo, hay que tener en cuenta que buena parte de las estrategias principales de las mujeres hoy en día para sortear las contradicciones familia- empleo "no será posible en un futuro próximo, cuando las últimas generaciones de abuelas inactivas y disponibles vaya desapareciendo y sustituyéndose por abuelas ocupadas y menos proclives a asumir el papel de madres sustitutas" (Tobío, 2002: 184).

De esta manera, la provisión de servicios de cuidado, su escasez o su suficiencia, en términos de servicios, públicos o privados, educativos, asistenciales y otros, comunitarios y familiares, configurarán las posibles estrategias de las mujeres, que dependen directamente de su situación familiar, su posición en términos de ingresos, sus valores, así como la disponibilidad y el acceso a los servicios públicos de cuidado. Así las cosas, 
"las estrategias de las "mujeres malabaristas" son opciones dinámicas y fluctuantes (...). Los arreglos suelen ser transitorios, y suponen una significativa capacidad de adaptación por parte de los involucrados (...). Las mujeres y sus familias pueden cambiar de una situación a otra en función de las oportunidades que les ofrece el contexto (Faur: 2014: 59).

El trabajo de cuidados no remunerado se traduce en una extensión del bienestar, transformando y manteniendo bienes y servicios de mercado y generando bienes y servicios nuevos, garantizando las necesidades afectivas relacionales, e interactuando con el mercado de trabajo productivo garantizando la disponibilidad de mano de obra (ONU Mujeres, 2014), y las posibilidades de conciliar para las mujeres dependen directamente de la posibilidad de minimizar las tensiones entre familia y empleo remunerado, porque "nos encontramos en un momento en que las mujeres pertenecen a dos mundos que solicitan su tiempo y su atención: el trabajo remunerado y el trabajo no remunerado en el hogar" (Fernández y Tobío, 2019: 112).

Esta superposición de las viejas responsabilidades domésticas y las nuevas responsabilidades laborales de las mujeres se convierte en un aumento del tiempo que dedican a ambos tipos de trabajo, dando lugar al efecto cansancio tanto físico como psíquico. Esto hace que buena parte de las estrategias de las mujeres consisten en sustituir y delegar parte del trabajo de cuidados hacia otras mujeres. En consecuencia, "la liberación de ciertas mujeres de una parte de la carga de lo doméstico y familiar se resuelve, fundamentalmente, a través de otras mujeres que asumen, bien en el marco de relaciones familiares basadas en mecanismos de reciprocidad y solidaridad, bien en el marco de las relaciones mercantiles atípicas que rigen en el mundo de lo privado" (Tobío, 2006: 28).

Es decir, el cuidado que no atienden las mujeres en sus hogares, lo atienden otras mujeres de fuera del hogar. Cabría pensar que, a la vez que las mujeres acceden al empleo remunerado, los hombres lo hicieran al trabajo de cuidado (Tobío, 2012). Habría así una redistribución justa y enriquecedora de ambos tipos de actividades. No existiría déficit de cuidado sino reorganización social de los tiempos dedicados a las distintas facetas de la vida (Tobío, 2017). Parece tan claro, que lo sorprendente es que no sea así. No lo es, aunque sí hay una ligera tendencia en ese sentido (Fernández y Tobío, 2019: 113). Y como señalan Addati et al. (2018), no se puede avanzar en la igualdad de género si no afrontamos la desigualdad la prestación de cuidados no remunerada a través del reconocimiento, la reducción y la redistribución del trabajo de cuidados no remunerado entre las familias y el Estado, pero también entre las mujeres y los hombres.

\section{Trabajo de cuidados remunerado}

Para empezar, hay que recordar que existen tres similitudes del trabajo doméstico no remunerado con el trabajo remunerado: tiene un coste en uso alternativo de tiempo, existe una clara distribución de tareas entre hombre y mujeres, y el producto es independiente de quien lo realiza. A su vez, el trabajo de cuidados no remunerado también tiene también similitudes con el trabajo no remunerado, donde se identifican básicamente cuatro tipos 
de tareas: las tareas domésticas, las tareas de subsistencia, trabajo voluntario y el trabajo de cuidados. Pero el protagonismo del cuidado se deriva del hecho de que éste tiene unas dimensiones que no tienen el otro tipo de tareas del trabajo no remunerado: implica un vínculo con otra persona.

Y aquí empieza el cuestionamiento sobre si el cuidado es trabajo no y podría asimilarse a otros tipos de trabajo o no. En este sentido destaca el hecho de que hay dimensiones de los cuidados que pueden estar en el trabajo o no estarlo, por su dimensión relacional y su dimensión emocional. Otro planteamiento es que, aunque sea un relación remunerada, siempre tienen un aspecto afectivo y moral, por lo que se debe reconocer también el valor social y económico de los componentes emocionales, relacionales y morales de los cuidados que hasta ahora están invisibilizados.

El trabajo de cuidado remunerado es cada vez una actividad económica más importante, tanto como gasto de los hogares empleadores como en los presupuestos públicos, a través de la contratación de profesionales de los servicios de cuidado (Ravazi, 2007). Básicamente existen dos motivos principales para contratar empleo de hogar para la provisión de cuidados. Por un lado, existen razones de diferenciación social, y por otro, razones de necesidad para atender cuidados que no pueden ser asumidos dentro de las familias. Generalmente este empleo está infravalorado, es altamente feminizado y no tiene reconocimiento social; además, se localiza dentro de la esfera doméstica y a pesar de su carácter mercantilizado entabla fuertes relaciones entre las personas empleadoras y las personas empleadas (ONU Mujeres, 2014), es decir, "fuera del entorno familiar, el trabajo de cuidado está marcado por la relación de servicio, de atención y preocupación por los otros. El trabajo se realiza cara a cara entre dos personas y genera lazos de proximidad" (Batthyány, 2015: 10).

Ahora bien, como recuerda Durán (2018: 248) que "el mercado convierte el trabajo, por definición, en mercancía (...). La capacidad de adquirir el cuidado/ mercancía, directa o indirectamente $(. .$.$) es proporcional a la capacidad adquisitiva del consumidor. Sin$ embargo, los hogares (...) se rigen por una lógica diferente, en la que se fusionan elementos del mercado laboral capitalista y de otros tipos de relaciones no competitivas y solidarias". Por otro lado, el volumen y las condiciones del trabajo del empleo de hogar ligado a los cuidados determina por un lado los niveles de desigualdad social y, por otro, la existencia o no de corresponsabilidad en la provisión de cuidados. El grado de desigualdad social está determinado por las diferencias salariales, dado que cuanto mayor es la diferencia entre hogares ricos y pobres, mayor es el empleo de hogar, mientras que, en el grado de corresponsabilidad, la provisión de cuidados está determinado por la mejor o peor provisión de servicios públicos (ONU Mujeres, 2014). En este sentido Durán (2018) advierte de la "la de hierro del cuidado" al señalar que "la capacidad de adquirir cuidado remunerado por los hogares es muy baja, e inversamente proporcional a la necesidad de cuidado".

En la actualidad existe una nueva clase social, que tiene una existencia real, relacionada con el volumen y el tipo de cuidados requeridos hoy por la sociedad, y con una relación específica respecto al proceso productivo. El cuidatoriado (Durán, 2018) nace de la 
necesidad de nombrar una realidad y poder tener herramientas para actuar sobre ella. La conversión de esta necesidad en una demanda organizada y un reto social no es automática, sino que requiere un largo proceso analítico sobre quien la sufre, el grado de consciencia y gravedad, cuáles son los elementos precipitadores y externos que facilitan la aparición de la conciencia, y las alianzas y conflictos que suscita. El concepto de cuidatoriado nace para poner fin a la idea de los cuidadores como un conglomerado de personas que cuidan, y convertirlo así en agente social con un papel en la estructura productiva.

Según Durán (2018), este cuidatoriado ha tenido una formación histórica muy rápida vinculada al envejecimiento y al desarrollo de los estados de bienestar; sus dos grandes grupos son dos grandes subclases, la que reciben remuneración directa por su trabajo y la que no, y no siempre coinciden en sus intereses, lo que puede generar riesgo de fractura interna; es un concepto que sirve para el autorreconocimiento y para pensar sobre la posibilidad de acciones colectivas; se trata de un sector desfavorecido en mercado de trabajo, con escasa remuneración, gran protagonismo de mujeres e inmigrantes; no tiene lugares ni tiempos de encuentro en los que conocerse y reconocerse para poder actuar conjuntamente, y la organización de su tiempo viene dada por las necesidades de quienes reciben el cuidado, no existen descansos garantizados semanales ni anuales ni nocturnos, sus jornadas de trabajo son más largas que las de los asalariados; carecen de derechos vinculados al trabajo asalariado (como sanidad, jubilación o seguridad social); su movilidad geográfica está limitada por quien recibe los cuidados en un sitio determinado, no hay posibilidad de ascensos laborales ni sociales, y son escasas las posibilidades de mejorar sus condiciones de vida; domina la falta de autocuidados, dado que tienen posibilidades mermadas de acceso al ocio, la cultura, la educación, la sexualidad o la participación política; y tiene dificultades para constituir organizaciones sindicales reivindicativas.

Es necesario dar valor social al trabajo de cuidados, mejorando los salarios de quienes cuidan, sus condiciones laborales, sus jornadas, su capacitación y su formación. Otro asunto importante es que tras trabajadoras del cuidado deben dar valor a su trabajo y deben reflexionar sobre sus prácticas como cuidadoras. Para ello, deben poder organizarse para poder reunirse, compartir su trabajo y discutir sobre él, y esto solo puede lograrse regulando adecuadamente su trabajo. En este sentido, el cuidatoriado necesita una mejor identificación, y puede hacerse desde distintas alternativas teóricas, todas válidas, pero con distintos objetivos estratégicos de cambio social y con distintas alianzas: Cuidadoras no remuneradas sin ingresos propios o con ingresos por otros motivos; Integración (o no) de productores y receptores del cuidado; Integración (o no) de cuidadoras remuneradas o no remuneradas; Integración (o no) de los que tiene el trabajo de cuidados como actividad principal o como actividad secundaria; Aplicación solo a los que se sienten identificados con el concepto por su función de cuidadores y miembros de un grupo social; y su ubicación dentro de la estructura de clases sociales.

El cuidatoriado es un concepto en construcción, que necesita definir sus límites y consensos para su consolidación, aunque su sola existencia pone de manifiesto la 
necesidad de políticas para garantizar el cuidado. Dado que el cuidatoriado carece de armas de reivindicación eficaces, y dado que el receptor de su trabajo no tiene capacidad para mejorar sus condiciones laborales, se traslada la responsabilidad al Estado (Durán, 2018). Y esta es una de las claves del papel del Estado en los cuidados, porque aún hoy, en todos los ámbitos, los significados atribuidos al trabajo de cuidados se asimilan a los atributos de la trabajadora que lo realiza.

Para avanzar en esta línea urge buscar alianzas que creen sinergias y afronten los retos pendientes. Quizá una opción sea una reforma disruptiva del sector ${ }^{1}$ tanto con relación a las actividades que lo componen como a los agentes involucrados. Si el trabajo de cuidados es una profesión más puede profesionalizarse, y quizá éste sea su futuro para garantizar los derechos y los deberes de los y las trabajadores de los cuidados, para alinear el trabajo de cuidados con el trabajo decente con relación a su protección contra los riesgos laborales, con sus cotizaciones y prestaciones sociales, o con la promoción de estructuras de representación colectiva y futuros esquemas de negociación colectiva, entre otras cosas.

\subsection{Las cadenas globales de cuidado}

Ha quedado patente que el cuidado es central para el trabajo de las mujeres fuera del hogar, a la vez que las mujeres son centrales para el trabajo de cuidados. A la vez, se está produciendo un incremento de la demanda de cuidados mientras se reduce la oferta, dada la reducción del tamaño de las familias, que reduce las posibilidades de proveer trabajo de cuidados en el seno de las propias familias, y dado también el envejecimiento de la población, que transforma profundamente la demanda de cuidados. Como señala Durán (2018:127), "la estructura demográfica es el mejor predictor global de la demanda de cuidados, pero la estructura social y política condiciona fuertemente la distribución de la producción de cuidados", toda vez que cubrir las necesidades de cuidado se ha convertido en una "condición estructural imprescindible para garantizar la subsistencia de un sistema económico y social” (Durán, 2018:111).

Es aquí donde aparecen una la de las claves del actual funcionamiento del mercado del cuidado, que liga oferta y demanda: las cadenas globales de cuidado: "La globalización ha creado complejos sistemas de sustitución del cuidado en cadenas que conectan a las madres de aquí a los menores o mayores de lejanos países a través de las inmigrantes cuidadoras que, a su vez, son sustituidas en sus lugares de origen por otras personas generalmente de la familia a las que transfieren la responsabilidad en esta materia" (Tobío, 2013: 25)

Tal y como señala Pérez Orozco (2011), las cadenas globales de cuidado se manifiestan en el cruce de las migraciones globales y las necesidades, también globales, de cuidado, y forman parte del actual proceso de globalización de los cuidados, siendo el lugar donde confluyen las transferencias de cuidados entre distintos hogares y familias, entendidas como dinámicas, flexibles y móviles, y donde el cuidado se analiza vinculado a un

\footnotetext{
${ }^{1}$ Idea sugerida por la profesora Gema Quintero en el IV Seminario General Sobre Trabajo Doméstico, organizado por el Instituto de Género de la Universidad Carlos III de Madrid, el pasado 27 de noviembre de 2020.
} 
beneficio, a un salario, y dentro de la lógica de la capacidad de reorganizar los cuidados tanto el origen como en destino de ese movimiento migratorio global. En origen, con el hecho de buscar trabajo fuera, se produce una crisis de la reproducción social dada la feminización de las migraciones (Benería, 2011: 363, 369) vinculadas a un proceso vital propio de las mujeres y no a un proyecto familiar, generando hogares transnacionales; en cambio, en destino, ante las crisis de los cuidados, se generan oportunidades laborales para esas mujeres migrantes, en los hogares empleadores.

Ahora bien, la globalización de los cuidados es clave en el proceso de globalización, pero es un elemento oculto dentro de ese proceso. Además, los cuidados permean las fronteras, de ahí que no puedan analizarse con la lógica de estado-nación, puesto que dan lugar a la internacionalización del trabajo de cuidados a la vez que aumenta la importancia de los agentes supranacionales de los sistemas y los arreglos del cuidado. En este sentido, hay que destacar tanto el papel de los agentes privados, en relación con la deslocalización de los servicios del cuidado y las empresas transnacionales que ofrecen servicios de cuidado, como de los agentes públicos, como los organismos multilaterales que definen las políticas económicas o los acuerdos bilaterales de Seguridad Social, entre otros (ONU, 2014: 148).

Así las cosas, podemos definir las cadenas globales de cuidados como redes transnacionales formadas con el objetivo de sostener cotidianamente la vida, vinculadas a diversos hogares, sobre la base de ejes de poder, ejes como el género, la clase social, el lugar de origen y el estatus migratorio. Estas cadenas globales de cuidados tienen sin duda un impacto socioeconómico, derivado entre otros asuntos, del hecho de que cuanta más desigualdad socioeconómica existe, más trabajo del hogar se contrata. Es decir, cuanto más barato es compara tiempo de vida de otra persona para los cuidados de mi familia, más trabajo de cuidados contrato. Esto genera un incremento constante de un estilo de vida cada vez más mercantilizado, sostenido en la desigualdad, de género, pero también, como señalábamos anteriormente, de la clase social, origen, raza o estatus migratorio (Herrera, 2016:10). La utilización desigual de recursos económicos y sociales que da lugar a distintos cuidados para distintas familias y personas genera a su vez diferencias en relación con la reproducción social (Kofman, 2016: 47-48). Y esto seguirá siendo así mientras persistan, entre regiones y países, las diferencias existentes tanto en renta, como en condiciones de vida y trabajo, y oportunidades de empleo (Durán, 2018: 263).

En resumen, como señala Durán (2018: 265), "el mercado laboral del cuidado es muy sensible a la internacionalización”, y a la regulación de la protección social y laboral en destino, así como de las propias migraciones. Dado que en estos empleos predomina la escasa inversión previa en capital, y son fácilmente fragmentables, dan como resultado que predomine la desregulación, la informalidad y la precariedad. Pero, aun así, son en muchas ocasiones la vía de entrada al mercado de trabajo de destino y a sus posibles beneficios sociales del Estado de Bienestar (Durán, 2018: 265). Este punto hay que situarlo en un contexto de "nociones de cuidado desterritorializadas, pero altamente determinadas por la territorialización: las migrantes negocian expectativas y regulaciones sobre el cuidado y la familia en al menos dos Estados nacionales" (Herrera, 2016:9), 
punto que no hay que perder de vista en el diseño de políticas para una ciudadanía global más inclusiva política económicas, migratorias, laborales y de cuidados.

\section{Algunas reflexiones finales}

Con relación a los cuidados, "los supuestos implícitos del Estado del bienestar ya no se sostienen (....). Las mujeres de la familia ya no pueden- ni seguramente quieren- continuar siendo las principales cuidadoras (ni que el cuidado sea su principal responsabilidad)" (Tobío, 2008: 101). Para Tronto (2017), las prioridades de la sociedad y la centralidad del mercado y las posiciones neoliberales han creado un déficit democrático sobre la atención y los cuidados a las personas, de manera que el sistema ha generado una ausencia de responsabilidades sobre el cuidado que ha desembocado en una irresponsabilidad privilegiada, que permite a los más favorecidos en la sociedad adquirir servicios de atención, delegar el trabajo de prestación de cuidados, y evitar la responsabilidad por la adecuación de la práctica en la atención, de manera que los que tienen más ingresos tienen una mayor capacidad de evitar las responsabilidades del cuidado y, por tanto, tienen, mediante ese privilegio, la oportunidad de ignorar las dificultades y no tener que afrontarlas, perpetuando esta situación de irresponsabilidad privilegiada, fuente de desigualdades sociales y de género. Consecuentemente, el trabajo de cuidados, tanto remunerado como no remunerado, se ha erigido en una de las claves del funcionamiento de las sociedades actuales, de manera que las crecientes necesidades de cuidado de mayores y menores, junto con la crisis de los cuidados, hace que sea cada vez más urgente conocer e intervenir en este sentido.

Con la teoría del cuidado social se da visibilidad al trabajo doméstico y de cuidados realizado por las mujeres, y en este cuidado social es donde convergen aspectos privados (preferencias, decisiones y recursos disponibles) con elementos sociales (mercado de trabajo, políticas familiares, etc.). Ambas dimensiones, público y privada, están interconectadas y son interdependientes, y todos ellos son claves para la organización social del cuidado hoy (Elizalde-San Miguel, 2018). Pero buena parte de estos elementos sociales no son "neutros" para la igualdad efectiva entre hombre y mujeres ni "para los distintos modelos familiares que implícita o explícitamente apoyan” (Batthyány, 2015:18).

Las desigualdades de género todavía existentes en la distribución del trabajo de cuidados no remunerado en los hogares, generan desigualdades laborales que se traducen en una mayor precariedad laboral de quienes lo realizan (Adati et al., 2018). Para no seguir reproduciendo estas desigualdades urge romper con los mecanismos que las perpetúan. Y para disponer de una correcta producción de cuidados (Durán, 2018), es importante conocer los desafíos de las políticas laborales de conciliación, dada la correlación entre ambas, y los efectos que el trabajo de cuidados no remunerado tiene sobre la calidad del empleo de las mujeres, por ejemplo, manteniéndolas en su rol de cuidadoras en el ámbito privado, o bien permitiendo socializar los costes del cuidado y facilitando la participación femenina en el mercado de trabajo y en la esfera pública (Faur y Pereyra, 2018). 
En este sentido, Elizalde- San Miguel (2019) establece los principios sobre los que debe desarrollarse el estudio comparado entre cuidados, políticas y regímenes, y conciliación, de manera que debe aplicarse la mirada de género en cada política, analizando si regula las relaciones de género o si permite que sea la inercia social la que determine el uso de la política pública, ya que "la inercia del cuidado como cuestión de mujeres persiste a pesar de que éstas desempeñan una creciente actividad en el mundo de lo público y de que hay políticas específicas para promover la incorporación de los hombres al cuidado" (Tobío, 2012: 417).

Como recuerdan Blofield y Martínez (2014), las políticas maternalistas reconocen la importancia de los cuidados, así como la capacidad de las mujeres para ser madres, de manera que el objetivo es premiar a las mujeres como responsables de la provisión de cuidados y lograr el reconocimiento social de los cuidados antes que reducir la brecha de género existente en su desempeño, y con esta concepción del cuidado qué fuerzan la idea de que es únicamente responsabilidad de las mujeres. Por el contrario, las políticas de corresponsabilidad social redistribuyen las responsabilidades de cuidados entre hombres y mujeres, pero también entre el Estado y las familias, consiguiendo además reducir las inequidades de género en el trabajo de cuidados, dado que tratan de "favorecer la ampliación del ejercicio de derechos sociales, económicos y políticos de las mujeres" (Aguirre et al. 2014: 50). En esta distribución de la responsabilidad social del cuidado es fundamental la presencia compartida del Estado, el mercado, la comunidad y las familias, pon un lado para garantizar el ejercicio del derecho al cuidado, y por otro lado para garantizar la igualdad social en el acceso y de género en la provisión (Marco y Rico, 2013).

Las políticas de cuidado tienen que fortalecerse y dar respuesta a los principales desafíos de esta actividad: "reconocer la cuestión del cuidado no como un problema personal, sino como uno público (...), que gravita, día a día, en el bienestar de la población y, por ende, en la posibilidad de cimentar una sociedad con mayor igualdad" (Faur y Pereyra, 2018: 530). Se trata de construir sistemas nacionales de cuidado que den respuesta al carácter multidimensional de los cuidados, haciendo hincapié en las políticas públicas intersectoriales que, de forma articulada, equilibren el diseño técnico y la dimensión política del sistema, bajo "la definición del cuidado como un bien público, en el sentido de que toda la sociedad se beneficia del mismo" (Marco y Rico, 2013: 18), de manera que se avance hacia un "nuevo pacto social donde se reconozca por una parte, la provisión cotidiana de cuidados, como un trabajo tan necesario como injustamente distribuido y retribuido; y, por la otra, la diversidad de modalidades en qué se provea: de manera formal e informal , remunerada y no remunerada, pública y privada, individual y colectiva" (Marco y Rico, 2013:17).

Addati et al. (2018) recuerdan que, a pesar de que se escudan en la falta de recursos, países con estructuras socioeconómicas y producto interior bruto similares muestran distintas políticas de cuidado, lo que pone de manifiesto la importancia tanto de las prioridades políticas como de la voluntad política de ampliar el espacio fiscal para adecuar y expandir las políticas de cuidado. Solo los países que plantean la igualdad de género 
como un objetivo explícito e incorporan la perspectiva de género en el diseño de sus políticas, consiguen redistribuir el trabajo de cuidados y, por tanto, lograr mayores niveles de corresponsabilidad, frente a los modelos de conciliación reduccionistas y feminizados, que no consiguen visibilizar el papel central del cuidado para el sostenimiento de nuestras vidas (Elizalde- San Miguel, 2018).

"Abordar la conciliación desde una perspectiva integral supone, por tanto, la definición de una modalidad de articulación familia-empleo y la puesta en marcha de políticas concretas que la desarrollen. Pero (...) supone ir más allá de las acciones directas por parte del Estado. Supone partir de las transformaciones en las relaciones de género y en la familia que son a su vez causa y efecto de la asunción de nuevas responsabilidades de aportación económica por parte de las mujeres. Desean asumirlas, pero además, la economía y la sociedad necesitan que lo haga (...). No se trata- o no debería tratarse- de un reajuste interno entre mujeres (...). Se trata, de un cambio ante el que deben acusar recibo los hombres, el mundo del trabajo y el Estado" (Tobío: 2006: 32). Avanzar en este sentido, "no es una decisión técnica sino política" (Durán, 2018: 483) y "el primer paso para empezar a dar soluciones es el reconocimiento de un problema (...). El objetivo (...) es contribuir a la discusión acerca de la definición de un modelo de futuro que sea realmente capaz de conciliar la participación de todos- mujeres y hombres- en el trabajo y en la familia" (Tobío, 2002: 184).

Otro de los grandes desafíos en torno al cuidado es el de "avanzar hacia su reconocimiento e inclusión positiva en las políticas públicas" (Batthyány, 2015: 12), y en esta línea, y con relación al futuro del cuidado, Addati et al. (2018) recuerdan que promover el trabajo decente para los y las trabajadoras del cuidado no sólo es posible, sino que es deseable. Como señala Elson (2008), esto pasa analizar como distribuir de forma más justa los costes y beneficios del trabajo de cuidados no remunerado, es decir, para por reconocer, reducir y redistribuirlo. En este sentido, las políticas de cuidados son transformadoras cuándo reconocen el valor del trabajo de cuidados no remunerado, cuando reducen ciertas formas de trabajo penosos y cuando se distribuyen las responsabilidades de cuidado entre hombres, mujeres, hogares y Estado. Se trata de reconocer su naturaleza, su extensión y su papel, entendiendo su contribución al desarrollo y al bienestar humano, atendiendo a quién lo está realizando, sin darlo por sentado y sin perder de vista las normas sociales y las desigualdades de género, así como las relaciones de poder en los que se enmarca (Esquivel, 2013).

Resulta necesario asimismo pensar sobre el hecho de que la "calidad del cuidado proporcionado depende directamente de las condiciones en que es ofrecido" (Batthyány: 2004: 52), por lo que es oportuno que estas políticas recompensen adecuadamente el trabajo de cuidados y promuevan su representación garantizando el diálogo social y la negociación colectiva de las trabajadoras y los trabajadores del cuidado, de forma tal que puedan mejorar sus condiciones laborales.

Igualmente, conviene detenerse en que la redistribución del trabajo de cuidados entre hombres y mujeres en los hogares no solo significa desafiar la distribución de tareas y los roles de género, sino también romper con las persistentes brechas laborales y salariales 
porque "mientras existan brechas de género en los salarios y las oportunidades laborales, los costos de oportunidad de asumir el trabajo doméstico y de cuidado no remunerado seguirán siendo más bajos para los hombres que para las mujeres. Esto hace económicamente racional que las familias y los hogares mantengan acuerdos basados en la generación de ingresos de los varones y el cuidado de las mujeres" (Esquivel, 2013:13). Y en este sentido, tal y como señala (Durán, 2018: 485), "más nos vale conocer cuál va a ser la carga y cómo va a redistribuirse entre las instituciones y los sujetos individuales, y según qué arreglos, porque ahí es donde radican las desigualdades más intensas”.

Las agendas políticas deben incluir las políticas del cuidado, regulando y asignando presupuestos (tanto para mantenimiento de los ingresos, como para transferencias y subsidios), ofreciendo servicios e infraestructuras de cuidado, facilitado tiempos y permisos para el cuidado, entre otras actuaciones. Las políticas del cuidado tienen la capacidad de ser transformadoras, en el sentido de que deben mitigar todas las formas de desigualdad (género, clase, origen), deben dar cumplimiento a los derechos humanos (a través del derecho a cuidar a y a ser cuidado) y deben ser capaces de transformar la responsabilidad social, la gobernanza y el concepto de ciudadanía (Esquivel y Kaufmann, 2017). En consecuencia, deben erigirse como marco alternativo para la teoría social y política (Tronto, 2017), porque si se considera el cuidado como parte de la condición humana (Tronto, 2005), debería ser la clave para modelar la economía, la política y las instituciones, que como recuerda Tobío (2006), estas transformaciones en las relaciones de género y en la familia, así como las nuevas responsabilidades de aportación económica por parte de las mujeres son necesarias hoy en día para una nueva articulación familiaempleo, pero también son necesarias para la economía y para la sociedad en su conjunto, y exigen políticas concretas que las desarrollen.

\section{Bibliografía}

ADDATI, Laura, CATTANEO, Umberto, ESQUIVEL, Valeria y VALARINO Isabel, Care work and care jobs for the future of decent work, Ginebra, International Labour Organization, 2018.

AGUIRRE, Rosario, BATTHYÁNY, Karina, GENTA, Natalia y PERROTTA, Valentina, "Los cuidados en la agenda de investigación y en la políticas públicas en Uruguay", Íconos. Revista de Ciencias Sociales, 2014, $\mathrm{n}^{\circ} .50$.

ANDERSON, Janine, "Nuevas políticas sociales de producción y reproducción", en ARRIAGADA, Irma (ed.), Futuro de las familias y desafíos para las políticas, CEPAL Serie Seminarios y conferencias, 2008, $\mathrm{n}^{\circ} 52$.

ARANGO, Luz Gabriela, "Cuidado, trabajo emocional y mercado: los servicios estéticos y corporales", Revista Latinoamericana de Estudios de Familia, 2015, n 7.

BATHYÁNY, Karina, "Cuidado infantil y trabajo ¿Un desafío exclusivamente femenino?, CINTERFOR, 2004. 
BATHYÁNY, Karina, "Las políticas y el cuidado en América Latina. Una mirada a las experiencias regionales”, CEPAL-Serie Asuntos de Género, 2015, nº 124.

BENERÍA, Lourdes, "Crisis de los cuidados, migración internacional y políticas públicas", en CARRASCO, Cristina, BORDERÍAS, Cristina y TORNS, Teresa, El trabajo de cuidados. Historia, teoría y políticas, Madrid, La Catarata, 2011.

BENERÍA, Lourdes, "Reproduction, production and the sexual division of labour", Cambridge Journal of Economics, 1979, $\mathrm{n}^{\circ} 3$ (3).

BLOFIELD, Merike y MARTÍNEZ, Juliana, "Trabajo, familia y cambios en la política pública en América Lantina: equidad, maternalismo y corresponsabilidad", Revista CEPAL, 2014, $\mathrm{n}^{\circ} 114$.

CARRASCO, Cristina, BORDERÍAS, Cristina y TORNS, Teresa, El trabajo de cuidados. Historia, teoría y políticas, Madrid, La Catarata, 2011.

DALY, Mary y LEWIS, Jane, "El concepto de "social care" y el análisis de los estados de bienestar contemporáneos", CARRASCO, Cristina, BORDERÍAS, Cristina y TORNS, Teresa, El trabajo de cuidados. Historia, teoría y políticas, Madrid, La Catarata, 2011.

DALY, Mary y LEWIS, Jane, "The concept of social care and the analysis of contemporary welfare states", British Journal of Sociology, 2000, no 51 (2).

DURÁN, María Ángeles, La riqueza invisible del cuidado, Valencia, Universidad de Valencia, 2018.

ELIZALDE- SAN MIGUEL, Begoña, “¿Femenino e informal? El modelo tradicional de cuidados a examen desde una perspectiva demográfica”, Prisma Social, 2018, nº 21.

ELIZALDE SAN MIGUEL, Begoña, DÍAZ GANDASEGUI, Miguel y DÍAZ GORFINKIEL, Magdalena, "Crisis y Estado de Bienestar en el cuidado de menores: reflexiones conceptuales a partir de un estudio comparado de España y Noruega", Revista de Economía Crítica, 2015, nº 20.

ELSON, Diane, (1995), Male bias in the development process, Manchester University Press, New York, 1995.

ELSON, Diane, "The three R's of unpaid work: recognition, reduction and redistribution", en Expert group meeting of unpaid work, economic development and human wellbeing- UNDP, New York, 2008.

ESQUIVEL, Valeria y KAUFMANN, Andrea, Innovations in Care New Concepts, New Actors, New Policies, Friedrich Ebert Stiftung Study, National Research Institute for Social Development, 2017.

ESQUIVEL, Valeria, El cuidado en los hogares y en las comunidades, Informes de Investigación Oxfam, 2013. 
ESQUIVEL, Valeria, FAUR, Eleonor y JELIN, Elisabeth, "Hacia la conceptualización del cuidado: familia, mercado y estado", en Esquivel, V., Faur, E. y Jelin, E. (eds.): Las lógicas del cuidado infantil. Entre las familias, el mercado y el estado, Ed IDES, 2012.

FAUR, Eleonor y PEREYRA, Francisca, "Gramáticas del cuidado", en PIOVANI, J. I. y SALVIA, A. (coord.), La Argentina en el siglo XXI. Cómo somos, vivimos y convivimos en una sociedad desigual, Buenos Aires, Siglo XXI, 2018.

FAUR, Eleonor, (2014): El cuidado infantil en el Siglo XXI. Mujeres malabaristas en una sociedad desigual, Buenos Aires Siglo XXI, 2014.

FAUR, Eleonor, "Lógicas en tensión. Desencuentros entre oferta y demanda de servicios de cuidado en Buenos Aires”, Revista de Ciencias Sociales, 2011, nº 27.

FERNÁNDEZ, José Antonio y TOBÍO, Constanza, "Mujeres: entre el salario y el cuidado", Revista ICE, 2019, nº 918.

FISHER, Bérénice y TRONTO, Joan, "Towards a theory of caring”, en Circles of Care: Work and Identity in Women's Lives, ABEL, Emily NELSON, Margaret (eds), State University of New York Press, 1990.

FOLBRE, Nancy, "Engendering economics: new perspectives on women, work and demographic change", Annual World Bank Conference on Development Economics, Washington D.C., 1995.

FOLBRE, Nancy, Who pays for the kids? Gender and the structures of constraint, Nueva York, Routledge, 1994.

FRASER, Nancy, Iustitia Interrupta: Reflexiones críticas desde la posición postsocialista, Santafé de Bogotá, Siglo del hombre Ediciones, 1997.

GILLIGAN, Carol, In a different voice: psychological Theory and womens's development, Cambridge, MA, Harvard University Press, 1982.

GILLIGAN, Carol, La moral y la teoría. Psicología del desarrollo femenino, México DF, Fondo de Cultura Económica, 1985.

GRAHAM, Hilary, "Caring: a labour of love", en FINCH, Janet y GROVES, Dulcie (eds.), A labour of love: women, work and caring, Londres, Routledge and Kegan Paul, 1983.

HERRERA, Gioconda, "Trabajo doméstico, cuidados y familias transnacionales en América Latina: reflexiones sobre un campo en construcción", en Amérique Latine Histoire et Mémoire. Les Cahiers, 2016, $\mathrm{n}^{\circ} 31$.

HIMMELWEIT, Susan, "Domestic labor", en PETERSON, Janice y LEWIS, Margaret (eds.), The Eldgar Companion to Feminist Economics, 1999, nº 1 (2).

HIMMELWEIT, Susan, Inside the household from labor to care, London, Macmillan, 2000 .

JELIN, Elisabeth, Pan y afectos. La transformación de las familias, Buenos Aires, Fondo de Cultura Económica, 2010. 
KOFMAN, Eleonore, "Repensar los cuidados a la luz de la reproducción social", Investigaciones Feministas, 2016, nº 35.

LEITNER, Sigrid, "Varieties of Familialism: The Caring Function of the Family in Comparative Perspective”, European Societies, 2003, nº 5 (4).

LEWIS, Jane, “Género, envejecimiento y nuevo pacto social”, en CARRASCO, Cristina, BORDERÍAS, Cristina y TORNS, Teresa (eds.), El trabajo de cuidados. Historia, teoría y políticas, Ed. Catarata, Madrid, 2011.

MARCO, Flavia, y RICO, María Nieves, "Cuidado y políticas púbicas: debates y desarrollo de situación a nivel regional", en PAUTASSI, Laura y ZIBECCHI, Carla (coord.), "Las fronteras del cuidado. Agenda, derechos e infraestructura", Revista de Ciencias Sociales, 2013, vol. 27, $\mathrm{n}^{\mathrm{o}} 35$.

MONTAÑO, Sonia (2010), "El cuidado en acción", en MONTAÑO, Sonia y CALDERÓN, Coral (coord.), "El cuidado en acción. Entre el derecho y el trabajo", Cuadernos de la CEPAL, 2010, $\mathrm{n}^{\circ} 94$.

ONU Mujeres, Porqué nos preocupamos de los cuidados. Centro de capacitación de ONU Mujeres, 2014.

PAUTASSI, Laura, "El cuidado como cuestión social desde el enfoque de derechos", Serie mujer y desarrollo CEPAL, 2007, nº 87.

PAUTASSI, Laura, "El cuidado como derecho. Un camino virtuoso, un desafío inmediato", Revista de la Facultad de Derecho de México, 2018, n 272.

PÉREZ OROZCO, Amaia y LÓPEZ GIL, Silvia, Desigualdades a flor de piel: Cadenas globales de cuidados. Concreciones en el empleo del hogar y las políticas públicas, Santo Domingo, ONU Mujeres, 2011.

PÉREZ OROZCO, Amaia, "Crisis multidimensional y sostenibilidad de la vida", Investigaciones Feministas, 2011, n ${ }^{\circ} 2$.

PINEDA, Javier, “Trabajo de cuidado: mercantilización y desvalorización”, Revista CS, 2019, no especial.

RAVAZI, Shahra, The political and social economy of care in a development context, gender and development, Ginebra, United Nations Research Institute for Social Development, 2007.

RICO, María Nieves, "El desafío de cuidar y ser cuidado en igualdad. Hacia el surgimiento de sistemas nacionales de cuidado", en HOPENHAYN, Martín, "Pactos sociales para una protección social más inclusiva. Experiencias, obstáculos y posibilidades en América Latina y Europa", Seminarios y Conferencias NNUU, 2014, $\mathrm{n}^{\circ} 76$.

TOBÍO SOLER, Constanza, "Conciliación o contradicción: cómo hacen las madres trabajadoras", Revista española de investigaciones sociológicas, 2002, nº 97. 
TOBÍO SOLER, Constanza, "Cuidado e identidad de género. De las madres que trabajan a los hombres que cuidan”, Revista Internacional de Sociología, 2012, vol. 70, n. 2.

TOBÍO SOLER, Constanza, "Estado y familia en el cuidado de las personas: sustitución o complemento", Cuadernos de Relaciones Laborales, 2013, vol. 3, $\mathrm{n}^{\circ} .1$.

TOBÍO SOLER, Constanza, "Nuevas formas familiares: Las madres que trabajan", Paisajes: Revista De Pensamiento Contemporáneo, 2006, nº 19.

TOBÍO SOLER, Constanza, "Redes familiares, género y política social en España y Francia", Política y Sociedad, 2008, vol. 45, nº 2.

TOBÍO SOLER, Constanza, “Trabajar y ser madre. La difícil conciliación”, Aequalitas: Revista jurídica de igualdad de oportunidades entre mujeres y hombres, 2003, nº 12, 2.

TOBÍO SOLER, Constanza, "Uneven paths: women and welfare in Italy and Spain", Journal of Gender Studies, 2017, nº 26.

TOBÍO SOLER, Constanza, Madres que trabajan. Dilemas y estrategias, Madrid, Cátedra, 2005.

TRONTO, Joan, "An ethic of care", en CUDD, Ann y ANDREASEN, Robin (eds.), Feminist theory: a philosophical anthology, Oxford, Blackwell Publishing, 2005.

TRONTO, Joan, "Theories of care as a challenge to Weberian paradigms in social science", en ENGSTER, Daniel y HAMINTONG, Maurice, Care ethics and political theory, Oxford, Oxford University Press, 2015.

TRONTO, Joan, "There is an alternative: homines curans and the limits of neoliberalism", International Journal of Care and Caring, 2017, $\mathrm{n}^{\circ} 1$.

TRONTO, Joan, Caring democracy: markets, equality and justice, New York, NYU Press, 2013.

TRONTO, Joan, Moral Boundaries: A political argument for an ethic of care, New York, Routledge, 1993. 